Nat1onal Bureau of Standards

Library, N.W. BIdg

DEC 71965

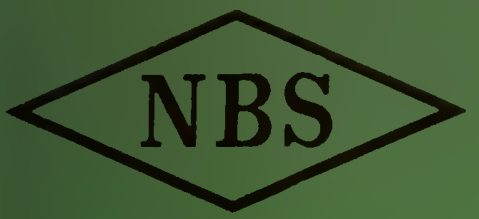

Eechnical Note

$\eta_{0.315}$

\title{
A METHOD FOR OBTAINING THE PARAMETERS OF ELECTRON-DENSITY PROFILES FROM TOPSIDE IONOGRAMS
}

R. S. LAWRENCE AND MARGOT HALLENBECK

U. S. DEPARTMENT OF COMMERCE NATIONAL BUREAU OF STANDARDS 


\section{THE NATIONAL BUREAU OF STANDARDS}

The National Bureau of Standards is a principal focal point in the Federal Government for assuring maximum application of the physical and engineering sciences to the advancement of technology in industry and commerce. Its responsibilities include development and maintenance of the national standards of measurement, and the provisions of means for making measurements consistent with those standards; determination of physical constants and properties of materials; development of methods for testing materials, mechanisms, and structures, and making such tests as may be necessary, particularly for government agencies; cooperation in the establishment of standard practices for incorporation in codes and specifications; advisory service to government agencies on scientific and technical problems; invention and development of devices to serve special needs of the Government; assistance to industry, business, and consumers in the development and acceptance of commercial standards and simplified trade practice recommendations; administration of programs in cooperation with United States business groups and standards organizations for the development of international standards of practice; and maintenance of a clearinghouse for the collection and dissemination of scientific, technical, and engineering information. The scope of the Bureau's activities is suggested in the following listing of its four Institutes and their organizational units.

Institute for Basic Standards. Applied Mathematics. Electricity. Metrology. Mechanics. Heat. Atomic Physics. Physical Chemistry. Laboratory Astrophysics. * Radiation Physics. Radio Standards Laboratory:* Radio Standards Physics; Radio Standards Engineering. Office of Standard Reference Data.

Institute for Materials Research. Analytical Chemistry. Polymers. Metallurgy. Inorganic Materials. Reactor Radiations. Cryogenics." Materials Evaluation Laboratory. Office of Standard Reference Materials.

Institute for Applied Technology. Building Research. Information Technology. Performance Test Development. Electronic Instrumentation. Textile and Apparel Technology Center. Technical Analysis. Office of Weights and Measures. Office of Engineering Standards. Office of Invention and Innovation. Office of Technical Resources. Clearinghouse for Federal Scientific and Technical Information.**

Central Radio Propagation Laboratory.* Ionospheric Telecommunications. Tropospheric Telecommunications. Space Environment Forecasting. Aeronomy.

* Located at Boulder, Colorado 80301.

** Located at 5285 Port Royal Road, Springfield, Virginia 22171. 


\title{
NATIONAL BUREAU OF STANDARDS Eechnical Mote 315 \\ ISSUED August 3, 1965
}

\section{A METHOD FOR OBTAINING THE PARAMETERS OF ELECTRON-DENSITY PROFILES FROM TOPSIDE IONOGRAMS}

\author{
Robert S. Lawrence and Margot Hallenbeck \\ Central Radio Propagation Laboratory \\ National Bureau of Standards \\ Boulder, Colorado
}

\begin{abstract}
NBS Technical Notes are designed to supplement the Bureau's regular publications program. They provide a means for making available scientific data that are of transient or limited interest. Technical Notes may be listed or referred to in the open literature.
\end{abstract}



TABLE OF CONTENTS

Abstract . . . . . . . . . . . . . . . . . . . 1

1. Introduction . . . . . . . . . . . . . . . . 1

2. Description of the Computer Program . . . . . . . . . 5

3. Conclusions . . . . . . . . . . . . . . . 22

4. Acknowledgments . . . . . . . . . . . . . . 22

5. References ................ 23-24

6. Figures ................... . . 17-18 and $25-26$

7. Tables . . . . . . . . . . . . . . . 27-31 



\section{A METHOD FOR OBTAINING THE PARAMETERS OF}

\section{ELECTRON DENSITY PROFILES FROM TOPSIDE IONOGRAMS}

Robert S. Lawrence and Margot J. Hallenbeck

We present sample results of a model-fitting procedure which involves adjustment of physically meaningful parameters of a model ionosphere so as to minimize the mean square difference between the observed virtual depths and those calculated for the model. The adjustment is made subject to additional constraints such as (1) physically reasonable limits to the values of the parameters and (2) agreement with any available auxiliary information such as the electron density at the satellite. The method requires more computer time than do conventional methods but compensates by making extremely economical use of observational data. It has been demonstrated that the method will provide useful information from data which are too scanty to be usable by lamination or polynomial methods. When, as occasionally happens, the process fails to find a useful answer, the reason appears to be that the ionosphere cannot be represented by the model being used. On the other hand, the use of physical limits on the parameters seems to insure that erroneous or multiple solutions will not occur.

\section{INTRODUCTION}

Many methods are available for deriving information about the vertical distribution of electrons from sweep-frequency ionospheric soundings, One of the earliest of these, suggested by Appleton and Beynon [1940], involved the assumption that the profile of the ionosphere is approximately parabolic. With this assumption, three points on the ionogram were used to determine the parameters of the parabola. In fact, the electron distribution is much more complicated than a simple parabola, and for realistic results it is necessary to elaborate this simple procedure. 
Modern attempts at elaboration lie between two limiting types of approach. One of these, the "polynomial" approach, involves the use of a polynomial of high order to represent the entire ionosphere [Titheridge, 1961]. The other, the "lamination" method [Budden, 1961], involves a large number of slabs, each of which is assumed to have a linear variation of plasma frequency. Between these two extremes there exists many lamination methods which involve the use of non-linear slabs.

Such methods, with various elaborations to surmount practical difficulties, have been used quite successfuly to produce large numbers of useful electron-density profiles below the peak of the F region [Thomas et al., 1958; Wright et al., 1963]. With the advent of the first topside ionograms from the satellite-borne sounder, Alouette (1962 Beta Alpha One), it was only natural to use the same procedures to obtain topside profiles. Nelms [1963], Thomas et al. [1963], Doupnik [1963], Fitzenreiter and Blumle [1964], and Paul and Wright [1964], among others, have prepared computer programs for this purpose. These programs produce satisfactory topside profiles from the Alouette soundings and they have been widely used. 
The primary purpose for producing ionospheric profiles is, of course, to learn more about the physical conditions existing in the upper atmosphere, especially the involved processes of the formation, loss, and movement of the ions and free electrons. For example, at heights well above the $\mathrm{F}$ peak, the plasma scale height is determined by the slope of a semi-logarithmic plot of electron density. If the ionic composition is known, the plasma scale height gives a direct measurement of temperature. This type of reasoning has been carried several steps further. Rishbeth (see Calvert et al., 1964) for example, has compared topside profiles, deduced from ionograms by a lamination method, with a number of theoretical profiles based upon various assumptions about the temperature and ionic composition. In this way, he succeeded in determining values for several parameters of his model at heights well above the $F$ peak where production and loss processes could be neglected. The success of Rishbeth's approach using a small number of adjustable parameters led us to consider the possibility of mechanizing his method so that, with a computer, more data could be analyzed and more parameters could be adjusted with greater ease and objectivity . If a computer program to fit a model to a known profile is feasible, it is, conceptually, only a small step to consider a still more complex computer program which fits the parameters of the model directly to the ionogram. Both of these computer programs have been written and they operate successfully. It is the purpose of this paper to describe the methods used by these programs and to present sample results. 
There is a compelling reason for taking the second, and larger, of these two steps, thereby replacing the conventional determination of an electron-density profile. The conventional methods require observation of the virtual depth at a large number of frequencies; large, that is, compared to the number of parameters we hope to adjust. They are generally ill adapted to the use of incomplete ionograms or to the simultaneous use of bits and pieces of the ordinary and extraordinary traces and of the ground-reflected trace. Therefore, in the case of incomplete ionograms or data from the fixed-frequency topside sounder, 1964-51A (S-48) [.Knecht et al., 1962], the conventional methods are frequently quite incapable of producing accurate results.

To recapitulate, we are presenting a method of analysis which is applicable to cases where the ionospheric profile is reasonably smooth and which is particularly valuable for those cases where the number of data points is limited or some of the values are imprecisely known. Because of the complicated structure of the lower ionosphere, the method is not recommended for use with ground-based ionograms.

In this paper we illustrate our method with a particular model (Rishbeth's) for the upper ionosphere, a particular method of calculating virtual depths (VIRDEP), and a particular minimization process (MINMYZ). However, the reader must keep in mind that the success of the method is not based upon these particulars but rather upon the incorporation of non-rigid bounds on the individual variable parameters and upon the use of available constraints on the model as a whole. 


\section{DESCRIPTION OF THE COMPUTER PROGRAM}

The computer program is given: (I) an ionospheric model involving several adjustable parameters; (2) an initial set of parameters with their individual bounds; (3) the frequencies, modes (ordinary or extraordinary), and observed virtual depths of several pulses reflected back to a topside sounder; (4) any known information about the ionosphere which may serve as a constraint; and $(5$, essential information at the sounder - height, geomagnetic dip, and gyrofrequency. The program must then adjust the parameters of the model so that the theoretical virtual depths calculated from the model will best agree with the observed virtual depths. Implicit in this statement is the assumption that there is a unique solution which gives "best" agreement. The problem seems to the authors far too complicated to permit a mathematical demonstration of uniqueness, but experience suggests that, for practical cases, if a solution exists which gives reasonable agreement it is unique. We define best agreement as that which minimizes the mean square of the residuals.

From this statement of the problem we can already see two of the essential ingredients of the program. First, there is a subroutine, VIRDEP, that computes the virtual depth to be expected for a pulse of arbitrary frequency reflected from the model ionosphere. Second, there is a subroutine, MINMYZ, that tries to adjust a set of parameters in such a way as to minimize the sum of the squares of an arbitrary set of residuals which result from the use of those parameters. These subroutines are described later in some detail. 
Another essential ingredient of any practical program of this nature is a procedure for accepting bounds on the parameters and for accepting other constraints on the model. The parameters of the model are intended to have at least a modicum of physical meaning. We are not interested in any narrowly empirical solution which involves such unpalatable features as a negative amount of some atmospheric constituent, and we do not want the computer to spend time searching for such a solution. If we specify physically realistic bounds on the values which the parameters may take, we can ensure that the computer will find only acceptable solutions.

In addition, it is highly desirable to be able to include, as constraints, any pertinent information which might be available from independent sources. For example, the critical (penetration) frequency of the ionosphere might be known from ground-based observations, or the total electron content might be known from Faraday-rotation measurements of the satellite signal. Such information comprises a constraint on a function of several parameters rather than a bound on the value of any one parameter. The methods of handling bounds and constraints are detailed in a later paragraph. 
General operation The program must be given a set of initial values of the parameters. Its first task is to check to see whether these initial values satisfy all the constraints. Generally, they will fall within the specified bounds, but they may violate a constraint such as a known critical frequency or a known electron density at the sounder. If one of these constrains is violated, the program uses the subroutine MINMYZ to adjust the parameters until all constraints and bounds are satisfied. This process, which is relatively simple, reduces the amount of adjustment which will be needed later when virtual depths will have to be calculated laboriously for each trial model.

After a suitable set of parameters is obtained, the program uses MINMYZ again, this time trying to adjust the parameters so that the virtual depths calculated by VIRDEP will nearly agree with the observations and the parameters will continue to satisfy all bounds and constraints. If the actual ionosphere differs radically from any acceptable configuration of the model, there will be no solution. Experience suggests that when a solution is found it is unique, i.e., it does not depend upon the initial values assumed for the parameters. Failure to find a solution appears to indicate incompatibility between the data and the model. Provision is made for printing the current values of the parameters, the trial virtual depths, and a graph of the trial model profile as frequently as desired to check progress. Naturally, this information is always presented for the final result. 
The virtual depth subroutine, VIRDEP The virtual, or apparent, depth of reflection of a pulse from a topside sounder is

$$
d=\int_{h_{r}}^{h_{s}} \mu^{\prime} d h,
$$

where $h_{r}$ is the height of reflection of the pulse; $h_{s}$ is the height of the sounder; and $\mu^{\prime}$, the group refractive index of the ionosphere, is a complicated function of the sounding frequency, the electron density and the geomagnetic field. VIRDEP uses the formulation presented by Shinn and Whale [1952], assuming that the propagation is vertical and that the dip angle of the magnetic field is independent of height. VIRDEP assumes that the strength of the magnetic field varies inversely as the cube of the distance from the center of the earth.

Before integrating equation ( 1 ), VIRDEP must find $h_{r}$. Since our model is monotonic above $h_{\max }, h_{r}$ can be determined by an ordinary binary search.

VIRDEP divides the range of integration into several slabs of thickness averaging about $100 \mathrm{~km}$, the ones near the sounder being the thickest. In order to achieve an accuracy of one kilometer, 8-point Gaussian integration is required for each slab. The lowest slab presents a special problem because $\mu^{\prime}$ becomes infinite at $h_{r}$. The bottom kilometer of this slab is evaluated by an analytic integration which assumes a linear variation of electron density. In this case $\mu^{\prime}$ is approximated by the first of two terms of a series expansion given by Budden [1961]. 
The minimization process, MINMYZ MINMYZ is a gradient-projection subroutine developed by Slutz and Winkelman [1964]. Its purpose is to adjust a set of variables so as to minimize an arbitrary function of them. In the present application, the variables are the parameters of the model ionosphere and the function to be minimized involves the mean square difference between the observed virtual depths and the corresponding depths calculated by VIRDEP.

Given $m$ adjustable parameters $P_{i}$ and a procedure for computing $n(\geq m)$ errors (such as discrepancies in virtual depth) $E_{j}$, MINMYZ first evaluates numerically the partial derivatives $\partial \mathrm{E}_{j} / \partial \mathrm{P}_{i}$ for $j \leq n$ and all $i \leq m$. This is done by one-sided rather than central differencing in order to reduce from $2 m n$ to $m n+l$ the number of times VIRDEP must be used.

In geometrical terms, the operation of MINMYZ may be described as follows. From the array of partial derivatives, MINMYZ determines the gradient of the error surface in $(m+1)$-dimensional space and from the individual derivatives estimates the distance which that gradient should be projected to find a minimum. The step is taken and VIRDEP is used $n$ times to assess the result. Comparison of the actual changes in the errors with those which were expected permits MINMYZ to decide whether it will be profitable to take additional steps in the same direction. If so, they are taken, using VIRDEP $\mathrm{n}$ times to check the result of each step. MINMYZ continues until no further improvement can be made locally in that direction. The program may use MINMYZ several times to get new gradient directions. 
When MINMYZ finds a minimum there is naturally no assurance that it is the global minimum. It is the responsibility of the user to design the function which defines the errors so that there will be few, if any, .Iocal minima in which to become trapped. Our procedure for doing this includes the use of physical constraints and bounds on the parameters. These are described below. In addition, we have found it necessary to invent artificial definitions of the error for those cases where, in the trial ionosphere, the probing frequency cannot propagate in the vicinity of the sounder or where it penetrates all the way to the ground. Unless something special is done with these cases, the partial derivatives are zero and MINMYZ receives no indication of which way to go.

The accommodation of bounds and constraints At first glance, the present method seems to fall in the category of problems commoniy faced in operations research. Nonlinear programming involves the minimization (or maximization) of a given function of several variables while simultaneously satisfying a set of linear or nonlinear constraints on those variables. An enormous effort has been devoted to the solution of this economically important problem [see for example, Zoutendijk, 1960; or Rosen, 1961], and it is tempting to try to use here the results of that work. This seems to be a vain hope because of important differences in emphasis. The typical problem in operations research involves, perhaps, hundreds of variables, and the function to be minimized is a simple function of those variables. Furthermore, the bounds on the variables are absolutely rigid. 
As an example, the number of oil refineries which can be used to produce a specific grade of fuel cannot be negative nor can it exceed the total number available. Rigid bounds cause abrupt changes in the direction of progress toward a minimum and so may increase the number of calculations of the function to be minimized.

Our problem, on the other hand, involves a small number of variables (the parameters of the model), but the function to be minimized is extremely complicated. Its calculation involves many lengthy numerical integrations of the group refractive index. The refractive index is an involved function of the plasma frequency which, in turn, is a complicated function of the parameters. The bounds on our parameters are not, by nature, absolutely rigid. To be sure, the temperature cannot be negative, but we can give more information than that. We know that it probably lies between $500^{\circ} \mathrm{K}$ and $1500^{\circ} \mathrm{K}$ and we can specify those values as bounds, although we would be just as satisfied with an answer of $499^{\circ}$ as with $501^{\circ}$ 
Thus, we have chosen to ignore the absolutely bounded methods of operations research and to include our bounds and constraints in the error function to be minimized. In this way we tend to avoid an excessive number of calculations of our complicated error function. Each bound or constraint is expressed in terms of a function which can be treated in exactly the same way as a residual in virtual depth. In essence all errors are "normalized" to a virtual depth residual. For example, we have defined the "error", $\mathrm{E}_{\mathrm{T}}$, connected with temperature $T$ as

$$
E_{T}=30\left(\frac{1000-T}{500}\right)^{3}
$$

so that temperatures of $500^{\circ}$ or $1500^{\circ}$ would have the same effect on MINMYZ as would a virtual-depth residual of $30 \mathrm{~km}$, and temperatures venturing outside this range would rapidly become less acceptable. Likewise, an "error" of similar form is used for any of the available constraints. In the case of a constraint upon the critical frequency, we might require that a computed frequency, $f_{c}$ be within $0.1 \mathrm{Mc} / \mathrm{s}$ of the given frequency, $f_{g}$. The error would then be defined as

$$
E_{f}=10 \frac{\left(f_{c}-f_{g}\right)^{3}}{(0.1)^{3}} .
$$

The inclusion of these "errors" defined upon the variable parameters, themselves, and upon the given constraints lends much to the success of the method. It not only permits the incorporation of any extra information (constraints) into the final results, but it also helps to guarantee an acceptable solution by keeping the parameters within physically reasonable bounds. 
The final function to be minimized is the mean square value of all such errors and of all residuals between the observed and computed virtual depths. We describe the degree of failure of the program to make a perfect fit to the observations by evaluating the estimated rms error,

$$
s=\left[\frac{1}{n-k} \sum_{i=1}^{n} r_{i}^{2}\right]^{\frac{1}{2}}
$$

where $r_{i}$ are the residuals in virtual depth, $n$ is the number of observed virtual depths, and $\mathrm{k}$ is the number of independently adjustable parameters, i.e., the number of adjustable parameters reduced by the number of constraints and further reduced by one to allow approximately for the fact that all parameters are bounded.

Sample results We now illustrate our method with several examples which were run on the IBM 7090 computer. The model used in our examples involves the following adjustable parameters:

$h_{a}$ - the height at which the concentration of $0^{+}$equals the concentration of $\mathrm{He}^{+}(\mathrm{km})$

$\sigma$ - the ratio of concentration of $\mathrm{H}^{+}$and $\mathrm{He}^{+}$at height $\mathrm{h}_{\mathrm{a}}$

$\mathrm{N}_{\mathrm{a}}$ - the concentration of electrons at height $\mathrm{h}_{\mathrm{a}}\left(\mathrm{cm}^{-3}\right)$

T - the electron temperature $\left({ }^{\circ} \mathrm{K}\right)$

$\mathrm{h}_{\max }$ - the height of maximum electron density $(\mathrm{km})$.

The electron density $N_{h}$ at height $h(\mathrm{~km})$ is calculated from the parameters in the following way:

$$
\left[\frac{N_{h}}{N_{a}}\right]^{Z}=\frac{e^{-Z_{h}-e^{Z_{m}-Z_{h}}+e^{-Z_{h} / 4}+\sigma e^{-Z_{h} / 16}}}{2+\sigma},
$$


where

$$
\begin{aligned}
& Z_{h}=\frac{K\left(h-h_{a}\right)}{T\left(R_{0}+h_{a}\right)\left(R_{o}+h\right)} \\
& Z_{m}=\frac{K\left(h_{\text {max }}-h_{a}\right)}{T\left(R_{0}+h_{a}\right)\left(R_{0}+h_{\max }\right)} \\
& R_{0}=6370 \mathrm{~km} \\
& K=765.826 \times 10^{6}{ }^{\circ} \mathrm{Km} .
\end{aligned}
$$

We do not intend to try to justify this particular model, but only to illustrate our method with its use. The method should work as well for any reasonable model involving a similar number of parameters.

In the sample computer runs, functions of the form

$$
P_{n}\left(\frac{P_{m}-P_{c}}{P_{r}}\right)^{n}
$$

were used as "errors" for MHNMYZ in order to establish the following upper and lower bounds on the parameters:

$$
\begin{aligned}
& 500^{\circ} \mathrm{K}<\mathrm{T}<1500^{\circ} \mathrm{K} \\
& 0<\sigma<1.25 \\
& 375 \mathrm{~km}<\mathrm{h}_{\mathrm{a}}<900 \mathrm{~km} \\
& .5 \times 10^{4} \mathrm{~cm}^{-3}<\mathrm{N}_{\mathrm{a}}<5.5 \times 10^{4} \mathrm{~cm}^{-3} \\
& 100 \mathrm{~km}<\mathrm{h}_{\max }<400 \mathrm{~km} .
\end{aligned}
$$


The $\mathrm{P}_{m}$ is the mean value of the desired upper and lower bounds for each parameter, $P_{c}$ is the current value of the parameter, $P_{r}$ is the half-range of permitted variation for the parameter and is simply the difference between the upper bound and $P_{m}$, and $P_{n}$ is a "normalization" factor. In most computations it was 15 in order to make the effect of a parameter at the limit of its acceptable range comparable to a virtualdepth error of $15 \mathrm{~km}$. The power $\mathrm{n}$ is any odd positive integer; generally it was 3 but occasionally values up to 9 were used. The purpose of $n$ is to control the rate of increase of the "error" as the value of the particular parameter ventures outside the acceptable range. The samples we shall discuss involve several computer runs, numbered arbitrarily. Each run took about a minute of computer time. These cases involve the use of the program to find an ionospheric model consistent with various observed points from a particular Alouette ionogram. The ionogram was made at $3^{\text {h }} 47^{m} 40^{\text {S }}$ UT on October 1, 1962. The sounder was at a height of $1038 \mathrm{~km}$, located at $34^{\circ} .9 \mathrm{~N}$. latitude and $89^{\circ} .1 \mathrm{~W}$ longitude. The geomagnetic dip angle was 67 degrees, and the electron gyrofrequency at the sounder was $0.94 \mathrm{Mc} / \mathrm{s}$. We shall see that the results agree well with the true-height profile obtained from the same ionogram using the lamination method of Nelms [1963]. 
For the run which we have arbitrarily labeled \#4, we chose to scale from the ionogram the virtual depths at those frequencies which would have been observed by the fixed-frequency topside sounder, $196451 \mathrm{~A}$ (S-48). Only six virtual depths with corresponding frequencies and modes were used as input, and a mild constraint on the critical frequency was used. No constraint on the electron density at the sounder was used. Figure 1 displays the electron denșity profiles of the initial trial model and the final model. The model used in this case incorporated a "peak", i.e., it involved $h_{\max }$ as a parameter. Since the input data contain no information from which either $h_{\max }$ or the critical frequency could possibly be deduced, we made another run (run \#5), this time simplifying the model by omitting the factor which involves $h_{\max }$. The results of this run are shown in figure 2.

Agreement of the electron-density profiles is gratifying but only of secondary interest. Our chief concern is whether or not the method determines the parameters of the model uniquely and with acceptable accuracy. It is important that the final set of parameters be determined solely by the observed data and not by the particular initial parameters used for the trial model. This is the case when a satisfactory fit is obtained. An example is given in table 1 which summarizes the data illustrated in figures 1 and 2 and gives the parameter values that resulted. 


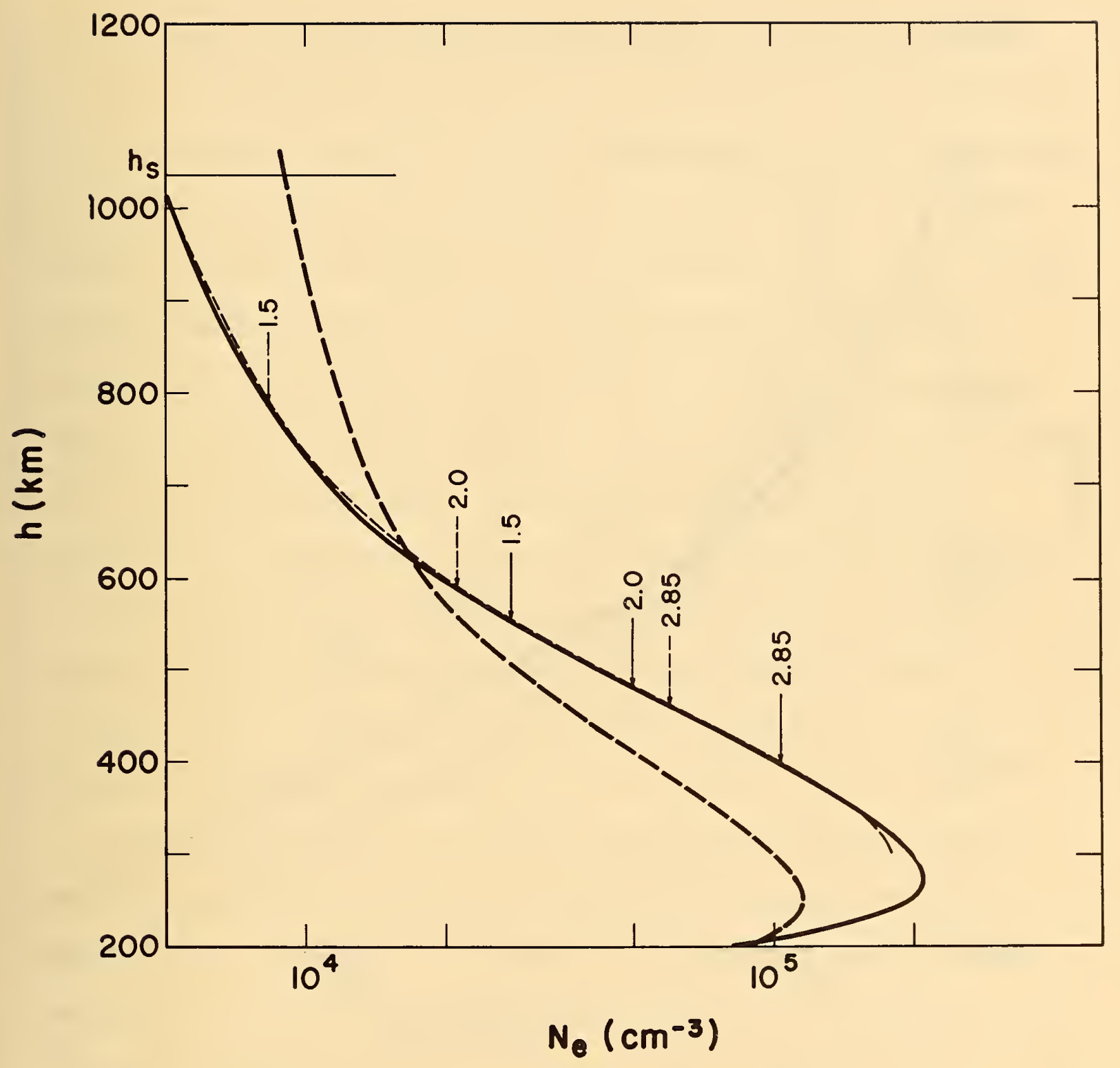

Figure 1. The electron-density profile (solid line) resulting from sample run \#4, is compared with the profile (thin dashed line) calculated by a lamination method using 29 virtual depths scaled from the extraordinary trace of the same ionogram. The initial trial parameters produced the profile shown by the thick dashed line. Vertical arrows show the true heights of reflection, corresponding to the virtual depths of the final model, for the six pulses that were used. The final estimated rms error for run \#4 of table $1=6 \mathrm{~km}$. 


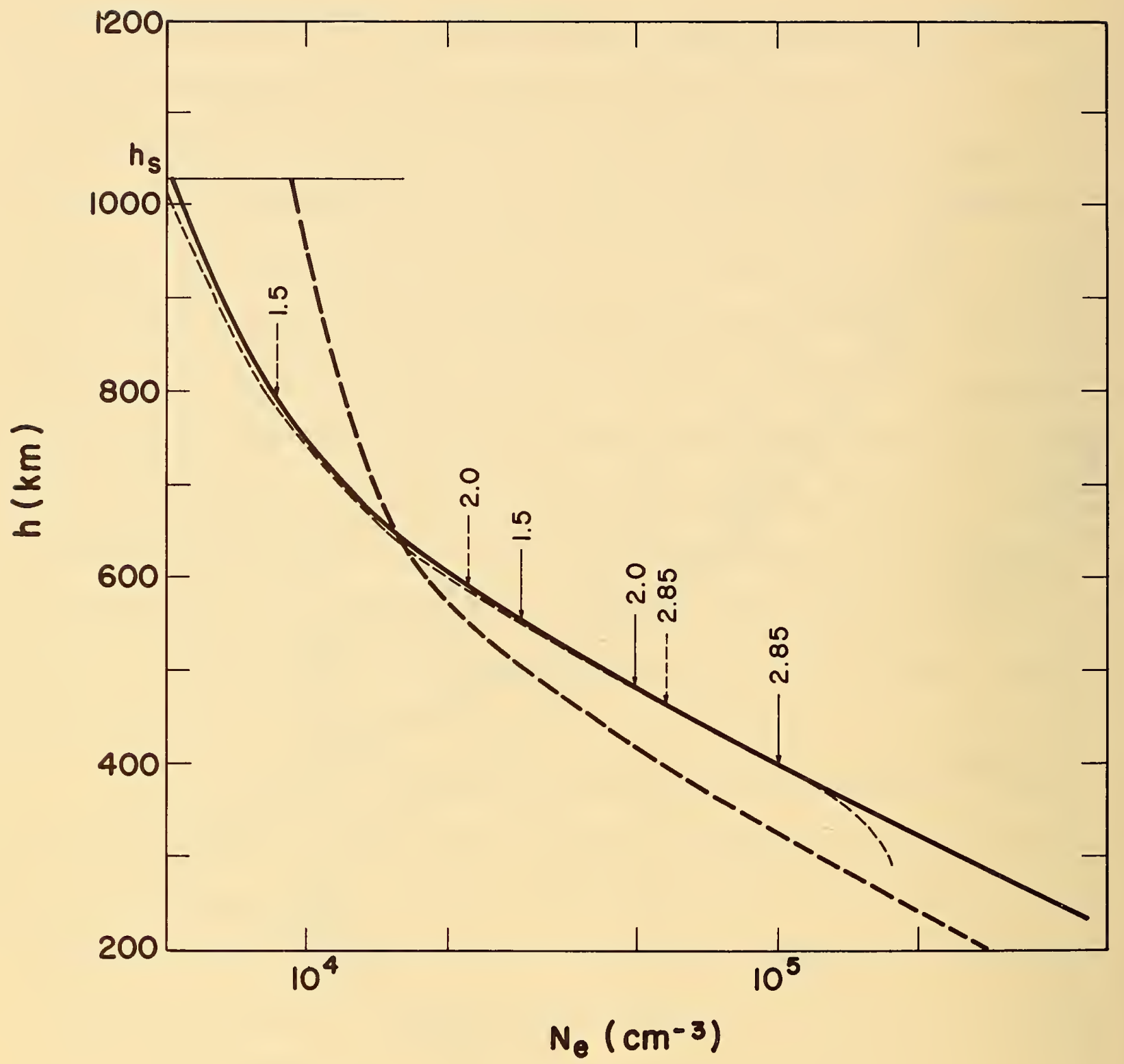

Figure 2. The result of sample run \#5. The only difference from figure $l$ is the omission of a peak in the model. Final estimated rms error for run \#5 of table $1=8 \mathrm{~km}$. 
In reference to the question of uniqueness of the final parameters we made two runs using the same input frequencies and virtual depths but with different sets of initial values for the parameters. These two runs used six virtual depths scaled from the extraordinary trace of the ionogram. The plasma frequency at the satellite was given as a constraint, and the plasma frequency at a probable height of the maximum electron density obtained by the lamination method was also given as a mild constraint. Table 2 provides a summary of the input data and the results. The resulting electron-density profiles for each case are shown in figures 3 and 4, respectively. Both figures show the initial models, the final models and also, for comparison, the profile obtained by the lamination method. Also shown in each figure is the result of the preliminary adjustment of the parameters which was made in order to satisfy all bounds and constraints.

We made several other runs to test the use of the various types of information which would have been available from the fixed frequency sounder. Three of these $(6,9$, and 10) are summarized in table 3 . The same initial values for the parameters were used in all cases and no added constraints were incorporated except mild constraints on the critical frequency in 9 and 10. From the particular ionogram which we were using, it was possible to scale the virtual depths of three of the specified fixed frequencies: $1.5,2.0$, and $2.85 \mathrm{Mc} / \mathrm{s}$. Both the extraordinary and the ordinary traces were present and were used for run \#6. We made run \#9 using only the 1.5 and the $2.0 \mathrm{Mc} / \mathrm{s}$ frequencies in order to investigate the capability of the method in dealing with very sketchy data. 
The program is designed to use delay times of ground-reflected pulses as additional data. Unfortunately, the particular ionogram which we had selected for analysis showed no ground-reflected traces. Consequently, we calculated the virtual depths to be expected for the extraordinary and ordinary ground traces at $5.47 \mathrm{Mc} / \mathrm{s}$ and used this information together with the data of run \#9 to make run \#10 in our analysis of the simulated S-48 data. Results appear in table 3. The final parameters, virtual depths, and true heights agree well among the three different runs.

With the fixed-frequency sounder there exists a possibility of identifying the ordinary and the extraordinary pulse of a particular frequency incorrectly. In order to study the convergence behavior of the method in such cases, we made run \#17 using both the ordinary and extraordinary modes of three S-48 frequencies but with the modes interchanged for the $2.0 \mathrm{Mc} / \mathrm{s}$ frequency. Table 4 summarizes the results of this run, and the corresponding run (\#3) using the correct data. The results for the run using the incorrect data show differences of more than $100 \mathrm{~km}$ between the observed and computed virtual depths while the corresponding differences for the correct run do not exceed $7 \mathrm{~km}$. The estimated rms error for the incorrect run was $107 \mathrm{~km}$, which indicates the lack of a good fit as compared to $6 \mathrm{~km}$ for the correct run. 
A summary of the final parameters and estimated rms errors of eight different runs is given in table 5. These runs utilize different minimization controls, different initial values of the parameters, various types of constraints such as the plasma frequency at the vehicle and $h_{\max }$, and virtual depths scaled at different frequencies. Two of the runs used data from the electron-density profile determined by the lamination method. Thus, the computation of virtual depths was eliminated in these cases. Table 6 gives the averages and standard deviations of the final parameters for sixteen different types of runs, including those described in table 5, and also includes Rishbeth's estimate for comparison. We see that, for practical purposes, the results are quite insensitive to initial values of the parameters.

The programs have been used subsequently for about 150 ionograms. More than three-fourths of these produced excellent results; the remainder failed to fit the data within the estimated error of observation. Some of the failures exhibited residuals which indicated that more complicated models would be needed to fit the observations; five or six stubbornly refused to make any progress at all. 


\section{CONCLUSIONS}

We have presented a method of analysis of topside ionograms which is particularly useful for sketchy or incomplete traces such as those from the fixed-frequency sounder. The method is a model-fitting method applicable to a wide variety of models and avoids the intermediate step of determining an explicit electron-density profile if only the parameters of the model are desired. The success of the method stems largely from the use of realistic bounds on the parameters and the ability to incorporate other constraints on the model. The method makes efficient use of input data, but requires more computing time than conventional true-height methods.

Tests with simulated data of the kind obtained from the fixedfrequency topside sounder show that several parameters of the ionosphere can be deduced from such records, even when it is impractical to produce complete electron-density profiles by conventional methods.

\section{ACKNOWLEDGMENTS}

We are indebted to R. W. Knecht and T. E. VanZandt for suggesting the problem, to $H$. Rishbeth for providing his formulation of the ionosphere model, to J. R. Winkelman for the subroutine MINMYZ, to G.I. Nelms for the lamination programs, and to E. I. Crow for helpfuI discussion. Financial support was provided by the National Aeronautics and Space Administration under Order No. S-2481-G. 
Appleton, E.V., and W. J. G. Beynon, "The application of ionospheric data to radio communication problems, Part I", Proc. Phys. Soc., 르, 518-533 (1940).

Budden, K. G., Radio Waves in the Ionosphere, Chapter 12, Cambridge University Press (1961).

Calvert, W., H. Rishbeth, and T. E. VanZandt, "Studies of Alouette Observations at the Central Radio Propagation Laboratory", IG Bulletin 83 in Trans. Amer. Geophys. Union 45, 398-402 (1964).

Doupnik, J. R., "A flexible method of determining the electron-density distribution in the ionosphere", Penn. State Univ. Iono. Res. Lab., Sci. Report No. 190 (August 1, 1963).

Fitzenreiter, R. J., and I. J. Blumle, "Analysis of topside sounder records", J. Geophys. Res., 69, 3, 407-415 (1964).

Knecht, R. W., T. E. VanZandt, and J. M. Watts, "The NASA fixed-frequency topside sounder program", in Electron Density Profiles in the Ionosphere and Exosphere, ed. B. Maehlum (Pergamon, Oxford) 246-260 (1962).

Nelms, G. I., (Defence Research Board, Ottawa, Canada) private communication (1963).

Paul, A. K., and J. W. Wright, "Electron-density profile analysis of topside sounder ionograms", J. Geophys. Res., 69, 7, 1431-1435 (1964).

Rosen, J. B., "The gradient projection method for nonlinear programming Part II. Nonlinear constraints", J. Soc. Indust. Appl. Math., 9, 4, 514-532 (1961).

Shinn, D. H., and H. A. Whale, "Group velocities and group heights from the magneto-ionic theory", J. Atmos. Terrest. Phys., 2, 85-105 (1952).

Slutz, R. J. and J. R. Winkelman, "Shape of the magnetospheric boundary under solar wind pressure", J. Geophys. Res. 69, 23, 4933-4948 (1964).

Thomas, J. O., J. Haselgrove, and A. Robbins, "The electron distribution in the ionosphere over Slough, I. Quiet days", J. Atmos. Terrest. Phys., 12, 1, 46-56 (1958).

Thomas, J. O., A. R. Long, and D. Westover, "The calculation of electron density profiles from topside sounder records", J. Geophys. Res., 68, 3237-3242 (1963). 
Titheridge, J. E., "A new method for the analysis of ionospheric $h^{\prime}(f)$ records", J. Atmos. Terrest. Phys., 21 , 1-12 (1961).

Wright, J. W., I. R. Wescott, and D. J. Brown, "Mean electron density variations of the quiet ionosphere, 10: December 1959", NBS (Boulder, Colorado) Tech. Note 40-10 (March 1963). Also Tech. Notes 40-1 through 40-9.

Zoutendijk, G., Methods of Feasible Directions, Elsevier Publishing Company, Ams terdam (1960). 


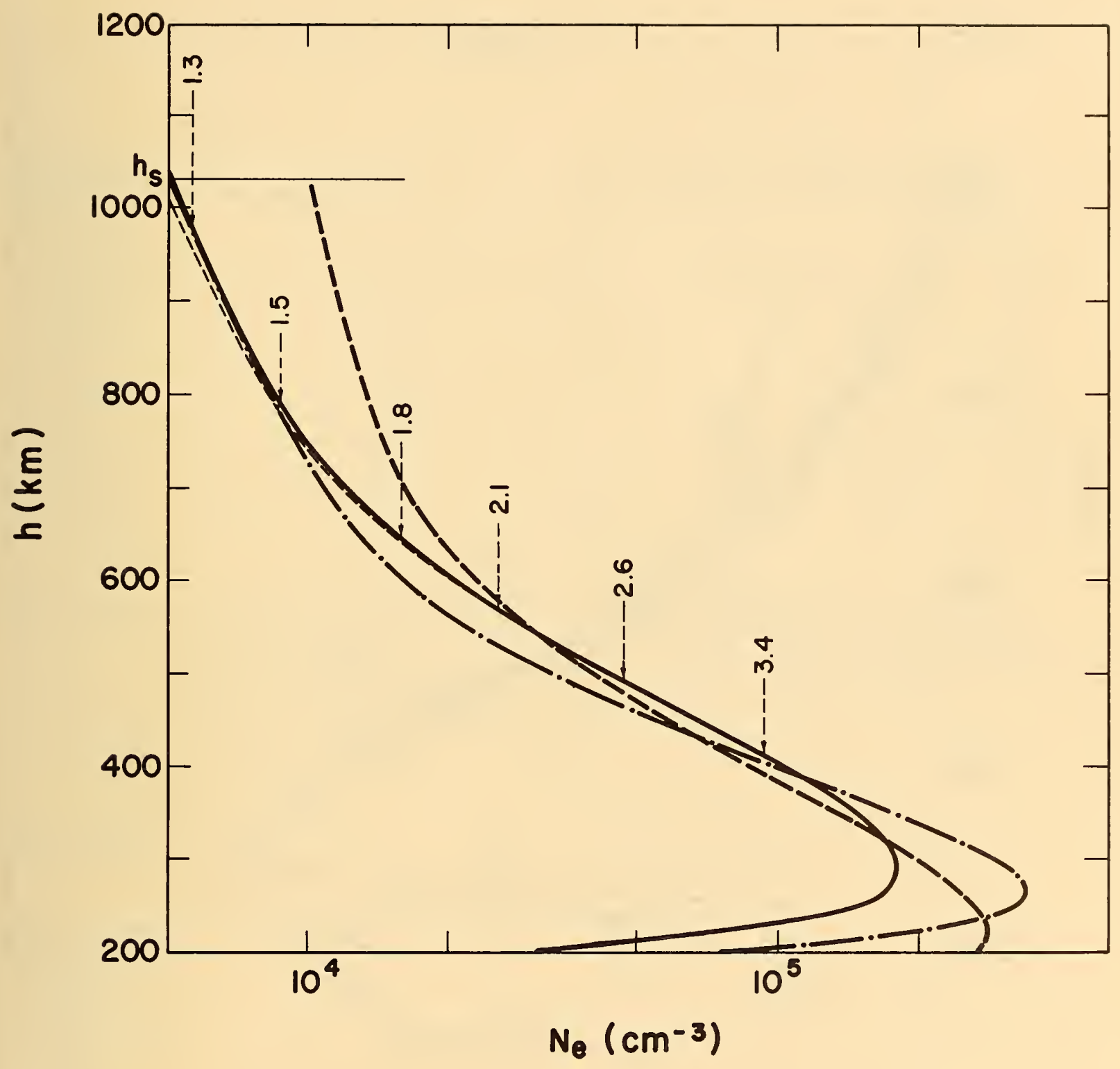

Figure 3. The electron-density profile (solid line) is compared with the profile (thick dashed line) produced by the initial trial parameters and the profile (dot-dashed line) obtained by preliminary adjustment to the bounds and constraints. The arrows show the true heights of reflection, corresponding to the virtual depths of the final model, for the six pulses that were used. The thin dashed line shows the profile produced by the lamination method. Final estimated rms error for run \#1 of table $2 \mathrm{~b}=3 \mathrm{~km}$. 


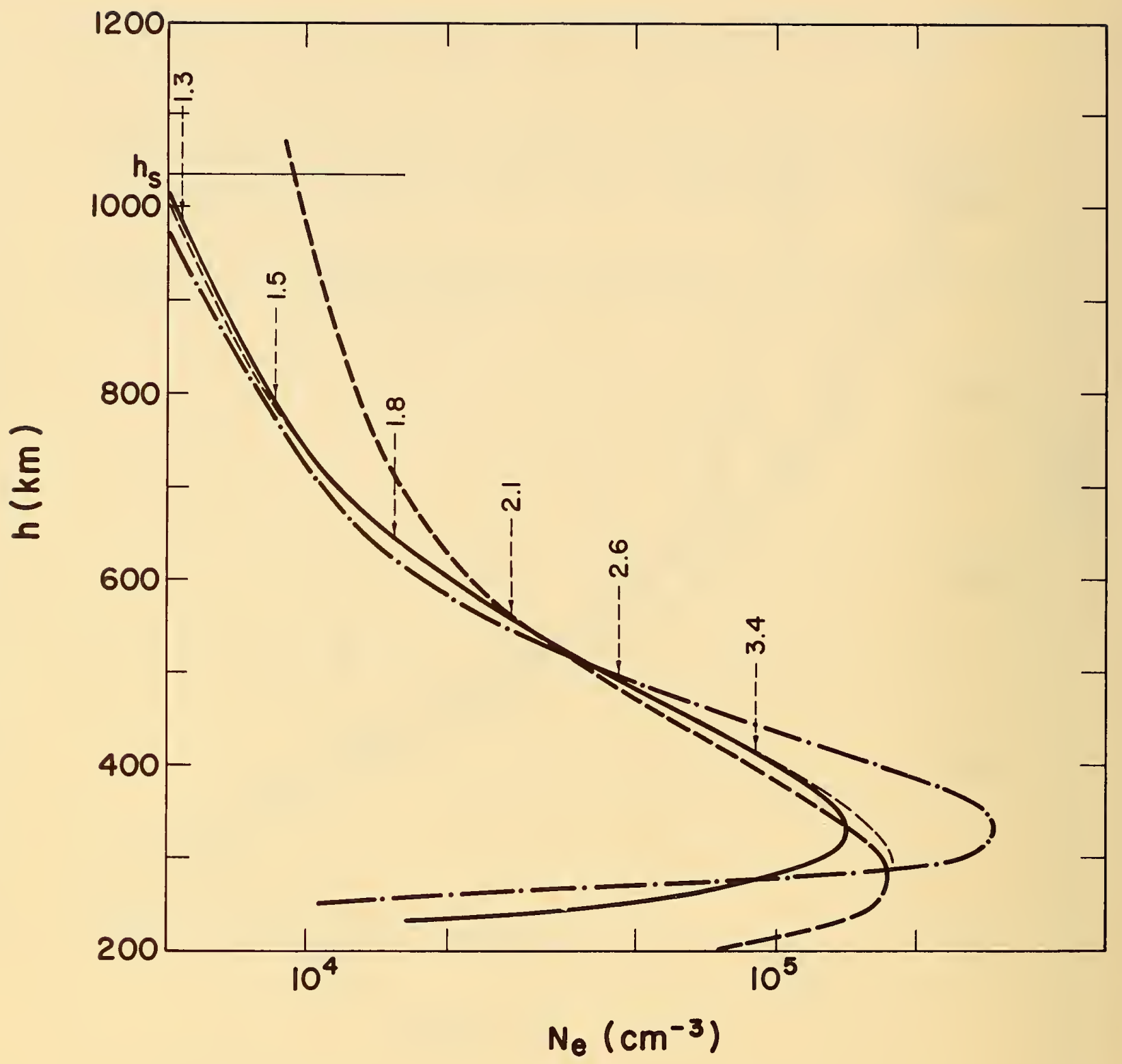

Figure 4. Same as figure 3 except that the model used different initial trial parameters. Final estimated rms error for run \#2 of table $2 \mathrm{~b}=6 \mathrm{~km}$. 


\section{Table 1:}

INPUT

Frequency Mode Virtual $(\mathrm{Mc} / \mathrm{s}) \quad$ Depth $(\mathrm{km})$

$1.5 \mathrm{X}$

1034

$2.0 \quad \mathrm{X}$

$2.85 \quad X$

1.50

$2.0 \quad 0$

2.85
878

838

713

744

825

OUTPUT
Error in Virtual Depth $(\mathrm{km})$

Run 4

Run 5

$\begin{array}{rr}7 & -2 \\ -2 & -1 \\ 4 & 8 \\ -5 & -3 \\ 5 & 6 \\ -2 & -10\end{array}$

True-height of Reflection ( $\mathrm{km}$ ) Run 4 Run 5

785792

$588 \quad 593$

$461 \quad 462$

$551 \quad 556$

$480 \quad 482$

$397 \quad 399$

Table la: Frequencies, virtual depths, and true-heights of reflection for the sample calculations illustrated in figures 1 and 2 . The estimated rms error for run 4 was $6 \mathrm{~km}$; the estimated rms error for run 5 was $8 \mathrm{~km}$. Both estimated rms errors are based on $n-k=3$ degrees of freedom.

Parameters

$\sigma$

$\mathrm{h}_{\max }$

ha

$\mathrm{N}$

T

西

.500

250

(km) $\left(\mathrm{cm}^{-3} \times 10^{-4}\right)$

Initial Model

575

2.00

1000

Final Model

Run 4

.053

274

651

1.43

878

Final Model

Run 5

.047

$---$

666

1.40

928

Rishbeth's

Estimated value

Estimated

.05

$--$

650

840

Uncertainty

.10

10

50

Table 1b: The initial and final parameters of the models illustrated in figures 1 and 2. For comparison are given the values which Rishbeth (1963) deduced from the same ionogram by comparing a number of theoretical curves with the lamination profile. 


\section{Table 2:}

INPUT

OUIPUT

\begin{tabular}{|c|c|c|c|c|c|c|}
\hline \multirow[t]{2}{*}{$\begin{array}{l}\text { Frequency } \\
(\mathrm{Mc} / \mathrm{s})\end{array}$} & \multirow[t]{2}{*}{ Mode } & \multirow[t]{2}{*}{$\begin{array}{l}\text { Virtual } \\
\text { Depth }(\mathrm{km})\end{array}$} & \multicolumn{2}{|c|}{$\begin{array}{l}\text { Error in Virtual } \\
\text { Depth }(\mathrm{km})\end{array}$} & \multicolumn{2}{|c|}{$\begin{array}{l}\text { True-height of } \\
\text { Reflection }(\mathrm{km})\end{array}$} \\
\hline & & & $\operatorname{Run} 1$ & Run 2 & Run 1 & Run 2 \\
\hline 1.3 & $\mathrm{X}$ & 600 & -2 & 8 & 989 & 984 \\
\hline 1.5 & $\mathrm{X}$ & 1034 & 3 & 2 & 795 & 792 \\
\hline 1.8 & $\mathrm{X}$ & 930 & 3 & 6 & 647 & 643 \\
\hline 2.1 & $\mathrm{X}$ & 861 & -2 & -4 & 573 & 570 \\
\hline 2.6 & $\mathrm{X}$ & 833 & 1 & -5 & 495 & 494 \\
\hline $3 \cdot 4$ & $\mathrm{X}$ & 863 & 0 & 2 & 413 & 412 \\
\hline Table 2a: & $\begin{array}{l}\text { Frequer } \\
\text { sample } \\
\text { rms err } \\
6 \mathrm{~km} \text {. } \\
\text { of free }\end{array}$ & $\begin{array}{l}\text { s, virtual } \\
\text { culations } \\
\text { for run I } \\
\text { h estimated } \\
\text { l. }\end{array}$ & $\begin{array}{l}\text { hs, and } \\
\text { trated } \\
\mathrm{km} \text {; es } \\
\text { errors }\end{array}$ & $\begin{array}{l}\text { e-heigh } \\
\text { igures } \\
\text { ted rms } \\
\text { based }\end{array}$ & $\begin{array}{l}\text { refl } \\
4 . \\
\text { r for } \\
-\mathrm{k}\end{array}$ & $\begin{array}{l}\text { ion for } \\
\text { imated } \\
\mathrm{n} 2 \text { was } \\
\text { degrees }\end{array}$ \\
\hline
\end{tabular}

Table 2a: Frequencies, virtual depths, and true-heights of reflection for sample calculations illustrated in figures 3 and 4 . Estimated rms error for run 1 was $3 \mathrm{~km}$; estimated rms error for run 2 was $6 \mathrm{~km}$. Both estimated rms errors are based on $\mathrm{n}-\mathrm{k}=4$ degrees of freedom.

Parameters

$\begin{array}{ccccc}\sigma & \begin{array}{c}\mathrm{h}_{\max } \\ (\mathrm{km})\end{array} & \begin{array}{c}\mathrm{h}_{\mathrm{a}} \\ (\mathrm{km})\end{array} & \begin{array}{c}\mathrm{N}_{\mathrm{a}} \\ \left(\mathrm{cm}^{-3} \times 10^{-4}\right)\end{array} & \begin{array}{c}\mathrm{T} \\ \left({ }^{\circ} \mathrm{K}\right)\end{array} \\ .500 & 225 & 600 & 2.25 & 900 \\ .029 & 294 & 648 & 1.54 & 872 \\ .400 & 275 & 600 & 2.25 & 900 \\ .032 & 328 & 635 & 1.62 & 828\end{array}$

Final Model

Run 2

Run 1

Initial Model Run 2

Initial Model

Run 1
Depth (km)

863 rror in Virtual
Depth $(\mathrm{km})$

Run 1 Run 2

$-2$

Final Model

Table 2b: The initial and final parameters of the models illustrated in figures 3 and 4 . 


\section{Table 3:}

INPUT

OUPUT

$\begin{array}{lrr}\begin{array}{c}\text { Frequency } \\ \text { (Mc/s) }\end{array} & \text { Mode } & \begin{array}{r}\text { Virtua } \\ \text { Depth (k }\end{array} \\ & & \\ 1.5 & \mathrm{X} & 1034 \\ 2.0 & \mathrm{X} & 878 \\ 2.85 & \mathrm{X} & 838 \\ 1.5 & 0 & 713 \\ 2.0 & 0 & 744 \\ 2.85 & 0 & 825 \\ 5.47 & \text { GX } & 1426 \\ 5.47 & \text { GO } & 1128\end{array}$

Error in Virtual

Depth $(\mathrm{km})$

Run 6 Run 9 Run $10 \quad$ Run 6 Run 9 Run 10

Table 3a: Frequencies, virtual depths and true-heights of reflection for sample S-48 data. Estimated rms error for run 6 was $11 \mathrm{~km}$ with $\mathrm{n}-\mathrm{k}=2$, run 9 was $10 \mathrm{~km}$ with $\mathrm{n}-\mathrm{k}=1$, and run 10 was $10 \mathrm{~km}$ with $n-k=3$ degrees of freedom.

Parameters

Run 6:

Ordinary

Extraordinary

$1.5,2.0,2.85$

$1.5,2.0,2.85$

$\begin{array}{rrrrrr}-2 & -2 & -8 & 792 & 810 & 833 \\ 3 & 8 & 11 & 590 & 597 & 608 \\ 4 & --- & --- & 462 & --- & --- \\ -2 & -6 & -10 & 553 & 560 & 570 \\ 3 & 0 & -6 & 481 & 487 & 496 \\ -14 & --- & --- & 400 & --- & --- \\ --- & --- & 2 & --- & --- & 0 \\ --- & --- & -1 & --- & --- & 0\end{array}$

Run 9:

Ordinary

$1.5,2.0$

Extraordinary $1.5,2.0$

Run 10:

Ordinary

$1.5,2.0$

Extraordinary 1.5, 2.0

Ground Ord. $\quad 5.47$

Ground Ext. $\quad 5.47$

$\sigma$

.050

.106

261

$\frac{h_{\max }}{(\mathrm{km})}$

251

$.061 \quad 260$ $\stackrel{h_{a}}{(\mathrm{~km})} \quad\left(\mathrm{cm}^{-3} \times 10^{-4}\right)$

1.48

652

653

1.55

884

Table 3b: Final parameters for sample S-48 data. 


\section{Table 4:}

INPUT

\begin{tabular}{|c|c|c|c|c|c|c|c|}
\hline \multirow[t]{2}{*}{$\begin{array}{l}\text { Frequency } \\
(\mathrm{Mc} / \mathrm{s})\end{array}$} & \multicolumn{2}{|r|}{ Mode } & \multirow[t]{2}{*}{$\begin{array}{l}\text { Virtual } \\
\text { Depth }(\mathrm{km})\end{array}$} & \multicolumn{2}{|c|}{$\begin{array}{l}\text { Error in Virtual } \\
\text { Depth }(\mathrm{km})\end{array}$} & \multicolumn{2}{|c|}{$\begin{array}{l}\text { True-height of } \\
\text { Reflection }(\mathrm{km})\end{array}$} \\
\hline & Run & 3 Run 17 & & Run 3 & Run 17 & Run 3 & Run 17 \\
\hline 1.5 & $\mathrm{X}$ & $\mathrm{X}$ & 1034 & 0 & 94 & 802 & 798 \\
\hline 2.0 & $\mathrm{X}$ & 0 & 878 & -2 & -104 & 599 & 486 \\
\hline 2.85 & $\mathrm{X}$ & $\mathrm{X}$ & 838 & 7 & 36 & 467 & 463 \\
\hline 1.5 & 0 & 0 & 713 & -5 & -1 & 562 & 571 \\
\hline 2.0 & 0 & $x$ & 744 & 4 & 112 & 487 & 611 \\
\hline 2.85 & 0 & 0 & 825 & -4 & 31 & 401 & 388 \\
\hline
\end{tabular}

Table 4: A test of the effect of mis-identifying ordinary and extraordinary echoes. The estimated rms error for run 3 was $6 \mathrm{~km}$ with $\mathrm{n}-\mathrm{k}=3$, whereas $107 \mathrm{~km}$ was the estimated rms error for run 17 based on $n-k=3$ degrees of freedom. 


$\begin{array}{ccccccc}\begin{array}{c}\text { Run } \\ \text { Number }\end{array} & \sigma & \begin{array}{c}\mathrm{h}_{\max } \\ (\mathrm{km})\end{array} & \begin{array}{c}\mathrm{h}_{\mathrm{a}} \\ (\mathrm{km})\end{array} & \begin{array}{c}\mathrm{N}_{\mathrm{a}} \\ \left(\mathrm{cm}^{-3} \times 10^{-4}\right)\end{array} & \begin{array}{c}\mathrm{T} \\ \left({ }^{\circ} \mathrm{K}\right)\end{array} & \begin{array}{c}\text { Estimated } \\ \text { rms error }\end{array} \\ 1 & .029 & 294 & 648 & 1.54 & 872 & 2.6 \mathrm{~km} \\ 2 & .032 & 328 & 635 & 1.62 & 828 & 6.3 \mathrm{~km} \\ 3 & .078 & 243 & 673 & 1.41 & 929 & 6.3 \mathrm{~km} \\ 4 & .053 & 274 & 651 & 1.43 & 878 & 6.3 \mathrm{~km} \\ 5 & .047 & -.-1 & 666 & 1.40 & 928 & 8.4 \mathrm{~km} \\ 6 & .050 & 251 & 652 & 1.48 & 896 & 11.0 \mathrm{~km} \\ 7 & .111 & 282 & 626 & 1.88 & 899 & .10 \mathrm{Mc} / \mathrm{s} \\ 8 & .109 & 283 & 631 & 1.82 & 899 & .07 \mathrm{Mc} / \mathrm{s}\end{array}$

Mean of

8 runs

.064

279

648

1.57

891

Standard

Deviation .030

26

15

.17

31

of 8 runs

Runs 1 and 2 used six extraordinary traces and the plasma frequency at the vehicle; runs $3,4,5$, and 6 used the extraordinary and ordinary trace of three S-48 frequencies; and runs 7 and 8 used nine and twentynine points respectively of the lamination profile. Five different sets of initial parameters were used.

\section{Table 6:}

$\sigma \quad \begin{array}{cccc}\mathrm{h}_{\max } & \mathrm{h}_{\mathrm{a}} & \mathrm{N}_{\mathrm{a}} & \mathrm{T} \\ (\mathrm{km}) & (\mathrm{km}) & \left(\mathrm{cm}^{-3} \times 10^{-4}\right) & \left({ }^{\circ} \mathrm{K}\right)\end{array}$

$\begin{array}{lccccc}\text { Mean of } 16 \text { runs } & .094 & 277 & 650 & 1.55 & 833 \\ \begin{array}{l}\text { Standard deviation } \\ \text { of } 16 \text { runs }\end{array} & .061 & 29 & 19 & .16 & 42 \\ \begin{array}{l}\text { Rishbeth's } \\ \text { Estimated value }\end{array} & .05 & --- & 650 & -.-- & 840 \\ \begin{array}{l}\text { Estimated } \\ \quad \text { Uncertainty }\end{array} & .10 & -.- & 10 & -.-- & 50\end{array}$

The sixteen different runs include the eight described in table 5. They use various data points, various initial sets of parameters, and a number of different constraints on the data. 


U.S. DEPARTMENT OF COMMERCE

WASHINGTON, D.C. 20230

U.S. DEPARTMENT OF COMMERCE

OFFICIAL BUSINESS 